\title{
THE AMERICA'S CHRONICALLY GAP SKIN-COLORS, THE BOURGEOUIS, AND THE BEE'S TENSION AS DISCOVERED IN AKEELAH: THE LOGO-THERAPHY APPROACH
}

\author{
Andra Fakhrian \\ Department of English Literature \\ Sultan Agung Islamic University Semarang \\ e-mail: Fakhrian.andra@gmail.com
}

\begin{abstract}
Akeelah, a black American teenager, who faces many obstacles to achieve her purpose, to win the bee. Jibes, less attention from her mother, family, and even the roughness words are often heard by her until she becomes uncivilized. In the other side, Dylan-bourgeois with the bee's tension are supported her pessimism to become unsure of her own ability. Moreover, a chronicle Gap Skin-Colors in America made people after she won the regional spelling bee. Thereof, Akeelah becomes more respectful and found the true meaning of life, all is full of love in all of sudden. Akeelah becomes more open minded after her brutal and indecent. Hence, in this research the author will elaborate the logo therapy theory in a way to give a solution for status quo from the literary work analysis of 'Akeelah and the Bee
\end{abstract}

Keywords: The logo-therapy theory, Status Quo, and Akeelah

\section{INTRODUCTION}

The status quo proceeds a portrayal of many teenagers who cannot restrain themselves or succeed against the interference from the outside factors that can reduce their confidence. Either the challenge of friends or insults, or even the history which triggers a distinction among of society. As a matter of fact, many teens fail and become pessimistic about the calamities that befall them, if they will tend to get frustrated, and insults. Nevertheless, the pessimism looks dominant raise of the bourgeois (a group of the rich) are dominated of an area. All of them spark a debate in the ability to defend themselves to keep moving forward or being isolated. In the other hand, in the psychology side, adolescent is still in unstable conditions, meanwhile the outside factors have big influences on their personalities and mentalities.

The problems above portray on the movie of Akeelah and the bee, with Akeelah as the major character, an American teenage girl. The film describes as a teenager who does not have good personality, vulgar behavior, and fearless of failure. But she is also isolated from her friends because of her 


\section{Edulite}

Journal of English Education, Literature, and Culture

Volume 1, Number 2, August 2016

behaviors and bad treatment from the people around. Akeelah's mother in the flurry of work thus less watched on her. Meanwhile, her father has died, her father's ideas become her great motivation to win the race for the spellingbee.com motion in the family. The harsh words that always come out to make Akeelah brutal and coarse behave well towards his friends. Her mother never supports her activities, until see forcedly to lie in order to reach her desire to follow the race of spelling bee.

Moreover, the other factors who break Akeelah's confidence when his brother said that "on the bee, the competitors are mostly dominated by the white Americans, they will judge you". As we all know that the tension of American's chronicle Gap Skin-Colors maybe still be felt by some people in the US. As Akeelah gets her tension on the bee, while everyone stars at her like she is being isolated from the white.

Glance of the American's white and black gap, in 1968, sociologist Otis Dudley Duncan imagined what a future American society would look like if all forms of racial discrimination were eliminated, so that the only differences in the life chances of black and white children stemmed from the lingering influence of inequalities that existed in the previous generation. Duncan's research indicated that family background factors, such as parents' education and occupations, did not explain black-white inequality, leaving racial discrimination as the likely culprit. If discrimination were eliminated, he reasoned, racial inequality would wither away over time. He wrote: "If we could eliminate the inheritance of race, in the sense of the exposure to discrimination experienced by Negroes, the inheritance of poverty in this group would take care of itself." Given that lawful discrimination was nearing an end, one might have guessed, at the time, that Duncan's vision would come to fruition with these societal changes.

Nevertheless, even if the nature of racial actually still exists, the tension is not higher than the past. This research purposes for teens and parents in the United States, and in all countries who have the same problem against racial, Bourgeois-tension, and the roughness in a family that had an impact on children as Akeelah. As an answer, in this study the author offers the logo- 
Fakhrian, The America's Chronically Gap Skin-Colors... therapy approach as Akeelah succeed to control herself as the affirmative action.

\section{A Glimpse of Akeelah}

Akeelah Anderson who is reluctantly talked into participating in her school's spelling bee by her principal. While Akeelah loves spelling, she is hesitant to participate in the contest because she knows that other students at her inner city middle school will look down on her.

Unfortunately, many of her fellow students look down on those who work to achieve academic excellence even though that is one of the most surefire ways to get out of the difficulties of the low-income existence they currently endure. Nevertheless, she acts so brutal and intimidates her friends when she gets affront from students. Moreover other factors such as lack of mutually agree in the family, a frequency of hearing harsh words are often and also other factors which causes her to be irreverent.

At school, her teacher also realizes that Akeelah actually has a special gift for spelling and encourages her to sign up for the school's spelling bee. A suggestion is also delivered by her principal, Mr. Welch, who would love to have his poverty-stricken school look good in the district. But Akeelah does not want to come across as a "brainiac" to her classmates. And besides, she said that "she doesn't even like her school and doesn't see why she should represent it". All this resistance is just making her low self-esteem. But she does completely and easily wins.

Mr. Welch has invited Dr. Larabee, a professor from ULCA and a former spelling bee champ, in order to be a coach for Akeelah. He is impressed with Akeelah but, even she does not have a good attitude to interact with people. Akeelah faces obstacles along the way. Many kids look down upon her as any kind of freak because she can spell so well. Even her own mother is torn between whether she should support her daughter's attempts to compete in spelling bees. Outside of Akeelah, her coach and her principal, very few people seem to think she has any chance at all of winning. 


\section{EduLite}

Journal of English Education, Literature, and Culture

But, as the movie goes on, Akeelah learns from her mother, her coach, and even her opponents in the spelling bees that there are things in life more important than winning. Lessons are learned about obedience, loyalty, and determination. The movie is syrupy sweet at times. And it definitely does not break any new ground, and all of sudden it changes her to be a new Akeelah.

Underlying the Theory

Here, in this research the author found the logo therapy approach in the movie as the affirmative action towards Akeelah. The Logo therapy is often subsumed under the headings of humanistic psychology and existential psychology (Ponsaran, 2007). Basically, logo therapy was called height psychology in response to the Freudian concept of depth psychology. Meanwhile, depth psychology focused on insights from the natural and unconscious processes within a person, but height psychology promoted the idea that people could transcend these natural processes (Pytell, 2003).

As Akeelah is getting pressure from the outside, but eventually she gets injected of the spirit and approach of love from her coach, friends, people and mother so that she feels more confident to win the bee.

Actually logo therapy is different from psychoanalysis as we commonly known, the methods are less retrospective and less introspective (Frankl, 1959). Besides, Logo therapy indicates on the future aspects of a patient's life, for the specifically the meaning that one intends to fulfill (Boeree, 2006). Logos is the Greek word, which denotes meaning. Hence, logo therapy focuses on a person's search for meaning. This search for meaning in one's life is postulated as the primary motivational force (Frankl, 1959). Frankl clarifies that this search for meaning does not have any relation to spirituality or religion, but strictly relates to finding purpose in one's life or tasks (Somani, 2009). Moreover, logo-therapists do not prescribe meaning to a patient but rather describe the process of how meaning is obtained in hopes of providing the patient with a sense of fulfillment (Thorne \& Henley 2005). Thus, logotherapy regards its assignment as that of assisting a patient to find meaning in life (Frankl, 1959). 
Fakhrian, The America's Chronically Gap Skin-Colors...

Logo therapy is composed of three basic principles. The first basic principle is that life has meaning in all circumstances, even despondent ones. The second principle is that the main motivational force is the desire to find meaning in life. Lastly, the third basic principle states that humanity has the freedom of attitudinal choice, even in situations of unchangeable affliction (Frankl, 1959). Thus, Frankl purports that people can discover meaning through creative, experiential, and attitudinal values (Hatt, 1965). Creative values consist of achievement of tasks such as painting a picture or tending a flowerbed (Boeree, 2006).

Experiential values consist of encountering another human, such as a loved one, or by experiencing the world through a state of receptivity such as appreciating natural beauty (Hatt, 1965). Attitudinal values speak of the potential to make meaningful choices in situations of suffering and adversity (Gelman \& Gallo, 2009). Frankl contends that everything can be taken away from a person but the freedom to choose one's attitude (Frankl, 1959). He stressed that people should not suffer unnecessarily in order find meaning but that meaning was possible when suffering is inevitable. For example, a person subjected to an incurable disease or placed in a concentration camp can still discover meaning even though his or her situation seems dire (Hatt, 1965). Moreover, tragic optimism means that people are capable of optimism in spite of the tragic triad. Frankl believes that all humans will be subjected to the tragic triad, which consists of guilt, death, and unavoidable suffering (Ponsaran, 2007).

Frankl notes that meaning in life differs from person to person and from situation to situation. Hence he asserts that there is not a general meaning in life for all of humanity but rather an idiosyncratic meaning that varies at any given moment (Frankl, 1959). Frankl points to the self-transcendence of human existence, which implies that each person can find purpose and meaning by being directed toward something or someone other than the self. His concept of self-transcendence is associated with the idea of the supermeaning (Hatt, 1965). The super-meaning refers to an ultimate meaning that exceeds the intellectual capacity of humanity. Philosophers often promote the idea that people need to endure the meaninglessness of life but Frankl 


\section{EduLite}

Journal of English Education, Literature, and Culture

suggests that humans instead are faced with the inability to understand the unlimited nature of meaningfulness, which is the super-meaning (Frankl, 1959).

A person's will to meaning can become frustrated. Frankl coined the term existential frustration to explain this phenomenon of misdirected meaning. Existential frustration can occur from prolonged periods of boredom and apathy (Zaiser, 2005). Frankl utilizes the metaphor of an existential vacuum to explain frustrated meaning. Meaninglessness is a hole, which creates a vacuum that must be filled. Since it is a vacuum, things quickly try to fill the void of meaninglessness.

However, most attempts to fill this sense of emptiness are merely temporary as the hole is filled with superficial things (Boeree, 2006). Furthermore, Frankl believed that common maladaptive behaviors such as depression, aggression, and addiction were caused by a misdirected sense of meaning (Thorne \& Henley 2005). He noted that every generation has its own has its own set of maladaptive behaviors, which he coined as the collective neurosis (Frankl, 1959).

Logo therapy has many applications in the modern medical, psychological, and business sectors. Several studies reveal the benefits of using logo therapy in these environments. One such study sought to evaluate the effects of a logo therapy program for adolescents with terminal cancer. The study revealed that logo therapy is effective in improving meaning in life and quality of life of late adolescents with terminal cancer. Furthermore, the studied revealed that logo therapy can be used a preventive measure to ensure adolescents experience minimal existential distress (Kang, Shim, Jeon, \& Koh, 2009).

\section{DISCUSSION}

Giving attention toward somebody will create a response, even it can be variety. In the movie of Akeelah and the Bee, the major character, Akeelah, is poor of attention from her mother and also her family. All decisions and everything of problems are handled by her alone. The outside factors are very 
Fakhrian, The America's Chronically Gap Skin-Colors...

dominant for influencing Akeelah until finally she acts rather brutal and indecent.

Below are some proves toward the glimpse of Akeelah;

\section{Akeelah's Brutality}

"Hey, freak.

We want you to take care of our English homework.

Everybody say you a brainiac. - $l$ ain't no brainiac.

Like hell you ain't! Always got them A's down, right?

Yeah, she's scared of us.

Don't run away" (06:28)

From the script quotation above, on the movie, Akeelah are tackling and fighting to her friends, her brutality is shown though.

\section{Akeelah Gets Jibes}

"Pulchritude." - P...

$P-U-L-C .$.

$R$...

l-T-U-D-E...

pulchritude?

That's incorrect. It's from the Latin root "pulcher"

and there's an $H$ after the $C$.

See? She ain't so smart.

(laughing)

- Run for it! See ya! - Bye, sweetie.

Akeelah, wait!

Where are you going? You did great.

You were spelling words $l$ don't know how to spell.

Mr. Welch, $l$ told you $l$ did not want to do this. They're laughing at me.

They laugh because you intimidate them." (11:41)

All of sudden she goes out because of jibes from her friends.

\section{American's Chronically Gap Skin colors Remaining}

"What you looking at? - Spelling bee.

Oh yeah, $l$ heard about that.

You going up against a bunch of rich white kids.

They gonna tear your black ass up." (16:34)

join the bee.

The responses of her brother suddenly break down her confident to 


\section{Akeelah's Insolent Attitude}

"You can leave now. - Excuse me?

- $l$ said you can leave. - How come?

Because l don't have time to waste on insolent little girls.

lnsolent? l ain't insol--

$l$ mean l'm not insolent.

lt's just the first thing you do is start doggin' on--

Criticizing the way l speak.

$l$ thought this was just about spelling words.

Well then, fine." (19:16)

All things are captured from Akeelah's attitude that everyone is easy to judge her, it tells from the cover.

At that time, Akeelah has been going through a difficulty, a sense of prestige to ask for help is increasing, with Akeelah arrogantly decided not to ask the coach to coach. On the other hand, her mother was busy and ignored her.

The bee's tension has felt by Akeelah, and she knows that Dylan, the bourgeois will be her rival, the atmosphere tells clearly that the tension becomes climax that she realizes the competitors are dominated by the white and the bourgeois. Whereas she is black and from the small family.

As the movies goes on, the affirmative action comes to Akeelah through love and attention that called by The Logo-therapy approach and then finally changes Akeelah. It delivers by Dr. Larabee. He keeps motivating Akeelah to not be afraid about herself and be a good girl. While Dr. Larabee asked Akeelah to read the letter on the wall, it stated, "Our deepest fear is not that we are inadequate. Our deepest fear is that we are powerful beyond measure. We ask ourselves 'Who am $l$ to be brilliant, gorgeous, talented and fabulous?' Actually, who are you not to be? "That words are simply changed Akeelah in understanding the meaning of life, and she becomes more open minded after that.

"Did you know your mama?

went to college right after high school?

No.

$l$ had a scholarship.

$l$ was gonna be a doctor.

What happened?

$l$ just felt so out of place at that school.

$l$ convinced myself 
Fakhrian, The America's Chronically Gap Skin-Colors...

that l was gonna fail.

So before that could happen, $l$ dropped out.

$l$ don't want you to do the same thing with this bee.

"Gabbro,"

a group of dark heavy rocks.

Can you spell it for me?

$G-A-B-R-O$,

gabbro?

Actually it's got two Bs.

You know, Akeelah, you ain't short on people who want to help you.

$l$ bet if you just look around, you got 50,000 coaches.

Starting with me."(01:11:19)

Her mother finally support her and give her a big motivation in supporting her passion to win the bee. Her mother help her to memorize the words, and the Akeelah got much coaches from friends and people, everyone loved her, she is not the old Akeelah since then. The logo therapy is actually a simple thing that parents or everyone can give to child, relatives or anyone by giving them attention and understand their passion and teach them to understand deeper about the passion is, until they understand the meaning of it. In the movie of Akeelah and the Bee, she acts with freely, because no one control her, the logo therapy is not given to her in a very first place, that's why in the status quo the juvenile teenagers are mostly found.

Finally, the author served the logo therapy approach as the treatment that Akeelah got on the movie which can be implemented to treat to the teenagers as a solution.

\section{CONCLUSION}

Bad treatments always linger teens while they are growing adults. They often haunt which have given great influences toward teen's behaviors. Moreover these unforgettable experiences can be any reference for teens to do something. It is undeniably true in their lives. It also happened toward Akeelah as the main character of the film "Akeelah and the Bee." A life without great attentions and guidance from beloved people around her makes Akeelah be uncivilized and disrespectful. Hence her behaviors are greatly influenced by her closed-environment like her friends.

All of the beyond above, Akeelah has also spirit from her father, even though he has died. Akeelah finds that his father's ideas can be constructed 
into the good ones to overcome her problems. She can turn around from bad to good. It is done well because of logo therapy concept. He get many obstacles to bring about her dreams, but by holding her dreams tightly, she can handle those problems wisely. She is not worried again about her challenges in living among multi-cultural society.

\section{REFERENCES}

Atchison, D. (Director and Producer). (2006). Akeelah and the Bee [Motion picture]. United States: Lions Gate Entertainment.

Crumbaugh, J., \& Carr, G. (1979). "Treatment of alcoholics with logotherapy." The International Journal of Addictions, 14(6), 847-853.

Fraternity mocks Black History Month with "Compton Cookout". Retrieved from http://www.ktla.com/news/landing/ktlacomptoncookout,0,2673438.story [2010, April 16].

Hatt, H. (1965). Existential analysis and logotherapy: The contribution of Viktor E Frankl. Encounter, 26(3), 330-339.

Huckin, T. N. (1995). Critical discourse analysis. The Journal of TESOL-France, 2, 95-112. KTLA-TV, Los Angeles (2010, February 18).

Ponsaran, A. G. (2007). The philosophical foundations of Viktor Frankl's logotherapy. Philippiniana Sacra, 42(125), 339-354. 